\title{
Acute Ischemic Stroke as a Presenting Feature of COVID-19 in a Young Adult
}

\author{
Ahmad Alikhani,**, Mohammad Ali Souraki Azad², Azaliya Pakzad and Amir Mohammad Beyzaee ${ }^{3}$ \\ ${ }^{1}$ Department of infectious diseases, Antimicrobial Resistance Research Center, Communicable Disease Institute, Razi Hospital, Mazandaran \\ University of Medical Sciences, Sari, Iran \\ ${ }^{2}$ General Neurosurgeon, Razi hospital, Mazandaran University of Medical Sciences, Sari, Iran \\ ${ }^{3}$ Faculty of Medicine, Research Committee student, Mazandaran University of Medical Sciences, Sari, Iran
}

${ }^{*}$ Corresponding author: Ahmad Alikhani, Ghaemshahr, Razi Hospital, Yousef Reza street, Mazandaran University of Medical Sciences, Sari, Iran, Tel: 0989112917065; E-mail: ahalikhani@yahoo.com

Received: 07 Nov, 2020 | Accepted: 25 Nov, 2020 | Published: 01 Dec, 2020

Citation: Alikhani A, Azad MAS, Pakzad A, Beyzaee AM (2020) Acute Ischemic Stroke as a Presenting Feature of COVID-19 in a Young Adult. Autoimmun Infec Dis 3(2): dx.doi.org/10.16966/2470-1025.128

Copyright: (c) 2020 Alikhani A, et al. This is an open-access article distributed under the terms of the Creative Commons Attribution License, which permits unrestricted use, distribution, and reproduction in any medium, provided the original author and source are credited.

\section{Abstract}

Introduction: Coronavirus primarily affects the respiratory organ and results in respiratory symptoms. However, this newly emergent virus is not entirely known; therefore, not all symptoms are defined yet. Several reports have shown that the virus has a tendency to infect the central nervous system. In this report, we present a patient with COVID-19 and concurrent neurological presentation who was positive for lung CT scan and positive anti-COVID-19 antibody.

Case presentation: A 35-year-old man was admitted to the hospital with vertigo, ataxia and sudden loss of consciousness as the initial symptoms, with the diagnosis of cereberal infarction. Two weeks after the stroke, he developed intermittent fever and headache. Myalgia and dry cough added. Lung CT scan and positive anti-COVID-19 antibody confirmed the COVID-19 infection as the definite diagnosis.

Conclusion: We recommend to follow-up the patient and keep on taking atorvastatin and anti-platelete medications (aspirin, plavix) beside risk factor evaluation in ischaemic stroke patients with COVID-19 infection. Also, early therapeutic anticoagulation with LMWH could be considered as a beneficial approach to reduce thromboembolism, but must be balanced against the risk of intracranial haemorrhage, including haemorrhagic transformation of the acute infarct.

Keywords: Coronavirus; Central nervous system; Ischaemic stroke

\section{Introduction}

The appearance of the novel severe acute respiratory syndrome coronavirus 2 (SARS- CoV-2) has led to a global pandemic with an unexpected global health consequence. In infected individuals, the virus primarily affects the respiratory organ and results in respiratory symptoms that are collectively coined as COVID-19 [1]. However, this newly emergent virus is not entirely known; therefore, not all symptoms are defined yet $[2,3]$. Numerous reports have shown that the virus has a tendency to infect the central nervous system (CNS). Therefore, caregivers and authorities are concerned [4,5].

Overall, neurological symptoms of COVID-19 infection are classified in two subtypes: life threatening symptoms such as Guillain Barre Syndrome and encephalitis, and moderate symptoms such as fatigue and myalgia [6]. As headaches and dizziness were reported as the dominant CNS symptoms in patients infected by COVID-19; also changing in smell and taste status have been the most common PNS reported symptoms [7].

Two separate case reports from Japan and China, patients with COVID-19 developed symptoms of meningitis. In both cases, polymerase chain reaction (PCR) analysis of the cerebrospinal fluid (CSF) samples were positive for SARS-CoV-2, which has shown that the virus has the potential to cross the blood-brain barrier [4,5]. The spectrum of CNS involvement by SARS-CoV-2 is very broad, ranging from meningitis or encephalitis to ischemic stroke, which is believed to be caused by thrombophilia $[8,9]$. However, the presence of SARSCoV-2 in CNS is not established in patients with COVID-19 and concurrent ischemic stroke [9].

In this report, we present a patient with COVID-19 and concurrent neurological presentation who was positive for lung CT scan and positiveanti-COVID-19 antibody. 


\section{Case Presentation}

A 35-year-old man was admitted to the hospital with vertigo, ataxia and sudden loss of consciousness. CT-Scan and MRI evaluation showed cereberal infarction and he was treated accordingly. Two weeks after the stroke, he developed intermittent fever and headache. Myalgia and dry cough added. Regarding to persistent fever, he referred to us for more evaluation. Nothing remarkable was found in the past medical history. Patient had a history of imprisonment and crack, heroin and methadone addiction (has been on recovery for the past two years). He admitted in ID ward and we did lung CT scan and picked up some lesions compatible to Covid-19. CNS findings and respiratory problems concomitantly guided us toward diseases to cause these two presentations.

Due to his high-risk history, thorough medical and laboratory evaluation was performed (Table 1). Electrocardiographic evaluation showed normal sinus rhythm and transthoracic echocardiography revealed no valvular abnormality. D-dimer value was not significant. Cervical CT Angiography revealed no vascular abnormality. Cerebral CT Angiography showed normal cranial vascular system. T2, FLAIR and DWI views of brain MRI (without contrast) showed large high signal area at the right cerebral hemisphere, small high signal focus in left occipital lobe due to acute ischemia (Figures 1,2). Chest CT scan (Figure 3) revealed a ground-glass opacity and segmental consolidation in the right upper lobe of the right lung; Although SARS-CoV-2 nasopharyngeal PCR test reported negative (sample got at the $3^{\text {rd }}$ week of the presentation), plasma anti-COVID-19 IgM and IgG antibody ELISA test was positive. The patient underwent treatment with a single dose of chloroquine $400 \mathrm{mg}$, and Kaletra (lopinavir/ritonavir) $400 \mathrm{mg}$ BD for five days. After 2 days, fever subsided and patient was discharged with fair general condition without any respiratory problems. We continued atorvastatin, aspirin and Plavix and referred back to his neurosurgeon.

\section{Discussion}

Our case was a 35-year-old man with cerebral infarction, as the initial presentation of Covid-19 infection. Two weeks after the stroke, he developed intermittent fever, headache, myalgia, dry coughand respiratory symptoms.

As we all know, acute stroke is a medical emergency even during the ongoing COVID-19 pandemic. Respiratory symptoms are the most common presentation of patients with COVID-19 infection, while other rare presentations include atypical gastrointestinal, cardiovascular, or neurological manifestations [10].

COVID-19 infection has been described as a risk factor for stroke [11]. SARS- CoV-2 infection has been associated with prothrombotic state, which can cause D-dimer elevation and arterial and venous thromboembolic events [12]. During severe COVID-19 infection, overwhelming quantities of proinflammatory cytokines are released. This phenomenon can lead to the activation of mononuclear and endothelial cells, producing tissue factors leading to coagulation activation and thrombin generation. Uncontrolled release of free thrombin in blood can activate platelet cells and lead to thrombosis [12]. Also, It has been suggested that COVID-19 might stimulate the antiphospholipid antibodies (aPL) as a mechanism of ischaemic stroke, although post-infection aPL are usually transient and unassociated with thrombosis [13]. Ischemic stroke has been documented in patients with COVID-19 [14]. However, their demographic and clinical status was different $[9,10,14-17]$. The incidence of cerebrovascular disease in patients with severe COVID-19 infection is around 5\% $[16,18]$. Patients with cerebrovascular disease were older and had a higher incidence of risk factors like diabetes mellitus, hypertension, coronary artery disease, and former cerebrovascular disease [16].

Beyrouti R, et al. reported six cases of COVID-19 infection with large vessel ischemic stroke presentation. All six patients had large vessel occlusion with raised serum level of D-dimer $(\geq 1000$ $\mu \mathrm{g} / \mathrm{L})$. Multiterritory infarcts were reported in three patients, concurrent venous thrombosis in 2 patients, and despite therapeutic

Table 1: Laboratory tests results.

\begin{tabular}{|c|c|c|c|}
\hline Tests & Result & Unit & Normal range \\
\hline Anti-nuclear antibody (ANA) & 20-Jan & Titer & $<1 / 80$ \\
\hline Anti-ds DNA & 1.1 & $\mathrm{IU} / \mathrm{ml}$ & $<100$ \\
\hline Anti-Ro & 0.19 & Index & $<1.1$ \\
\hline Anti-La & 0.18 & Index & $<1.1$ \\
\hline Anti-Phospholipid (IgM) & 1.8 & $\mathrm{Ru} / \mathrm{ml}$ & $<12$ \\
\hline Anti-Phospholipid (IgG) & 2.3 & $\mathrm{Ru} / \mathrm{ml}$ & $<12$ \\
\hline C-ANCA & $<1 / 10$ & Titer & $<1 / 10$ \\
\hline P-ANCA & $<1 / 10$ & Titer & $<1 / 10$ \\
\hline Anti-Cardiolipin (IgG) & 1.6 & $\mathrm{U} / \mathrm{ml}$ & $<12$ \\
\hline Anti-Cardiolipin (IgM) & 1.3 & $\mathrm{U} / \mathrm{ml}$ & $<12$ \\
\hline ENA Screen & $<0.50$ & Index & $<1$ \\
\hline Protein C & 85.8 & $\%$ & $70-140$ \\
\hline Protein S & 79 & $\%$ & $65-140$ \\
\hline PT & 13.5 & Second & $11-13.5$ \\
\hline PTT & 37 & Second & $25-35$ \\
\hline INR & 1.2 & Second & $0.8-1.1$ \\
\hline White Blood Cell count & 8700 & & $4500-11000$ \\
\hline Lymphocyte count & $\begin{array}{c}1157 \\
(13.3 \%)\end{array}$ & $/ \mu \mathrm{l}$ & $1000-4000$ \\
\hline Neutrophil count & $6612(76 \%)$ & $/ \mu \mathrm{l}$ & $1500-8000$ \\
\hline Platelets count & 225000 & $/ \mu l$ & $150-450 * 10^{3}$ \\
\hline Hemoglobin & 13 & $\begin{array}{c}\text { Grams/ } \\
\mathrm{dL}\end{array}$ & $13.5-17.5$ \\
\hline Blood Urea & 32 & $\mathrm{mg} / \mathrm{dL}$ & $13-43$ \\
\hline D-Dimer & 100 & $\mathrm{ng} / \mathrm{mL}$ & $<250$ \\
\hline Creatinine & 1 & $\mathrm{mg} / \mathrm{dL}$ & $0.6-1.2$ \\
\hline $\mathrm{Na}$ & 137 & $\mathrm{mEq} / \mathrm{L}$ & $135-145$ \\
\hline K & 3.8 & $\mathrm{mEq} / \mathrm{L}$ & $3.5-5.5$ \\
\hline ESR & 69 & $\mathrm{~mm} / \mathrm{hr}$ & $<15$ \\
\hline CRP & +++ & & Negative \\
\hline RPR & Negative & & \\
\hline Aspartate aminotransferase & 25 & $\mathrm{IU} / \mathrm{L}$ & May-40 \\
\hline Alanine aminotransferase & 56 & IU/L & $<45$ \\
\hline Alkaline phosphatase & 237 & $\mathrm{IU} / \mathrm{L}$ & $44-147$ \\
\hline Lactate dehydrogenase & 329 & $U / L$ & $140-280$ \\
\hline Creatine phosphokinase & 47 & $\mathrm{mcg} / \mathrm{L}$ & $<171$ \\
\hline U/A & Normal & & \\
\hline COVID-19 IgG & 2.73 & $\mathrm{U} / \mathrm{mL}$ & $<0.9$ \\
\hline COVID-19 IgM & 1.67 & $\mathrm{U} / \mathrm{mL}$ & $<0.9$ \\
\hline
\end{tabular}




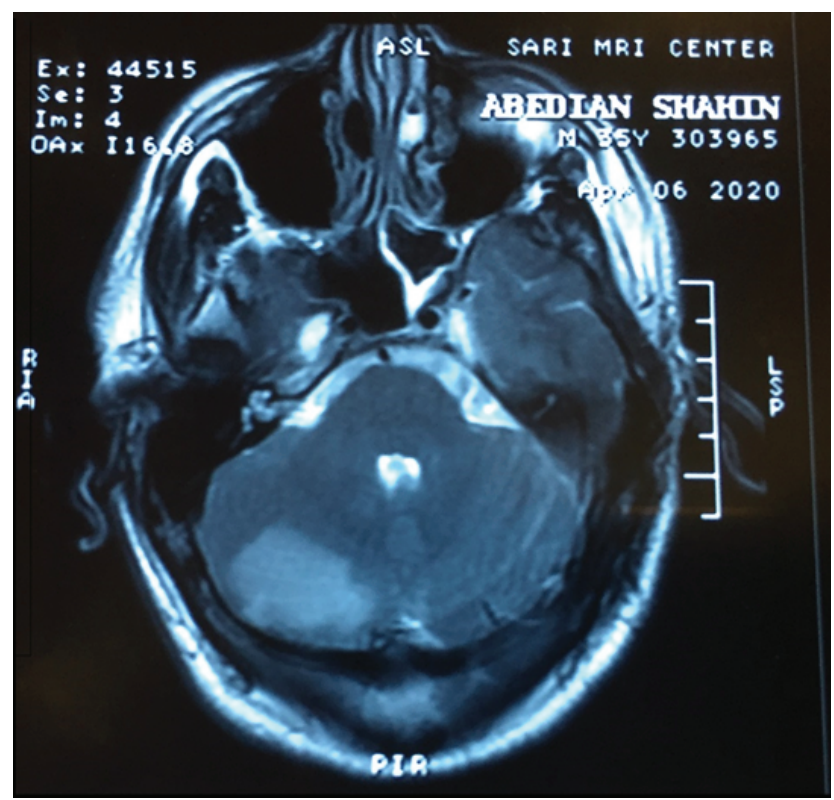

Figure 1: Brain MRI.

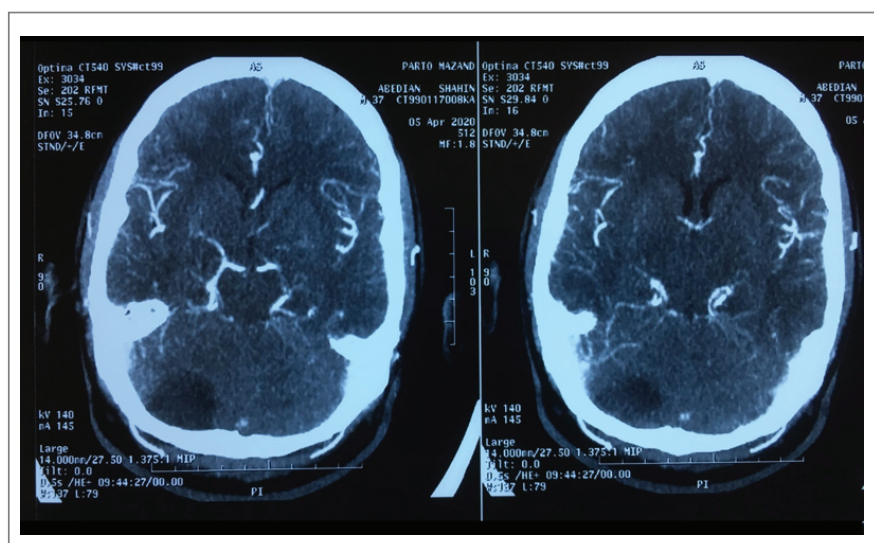

Figure 2: Brain MRI.

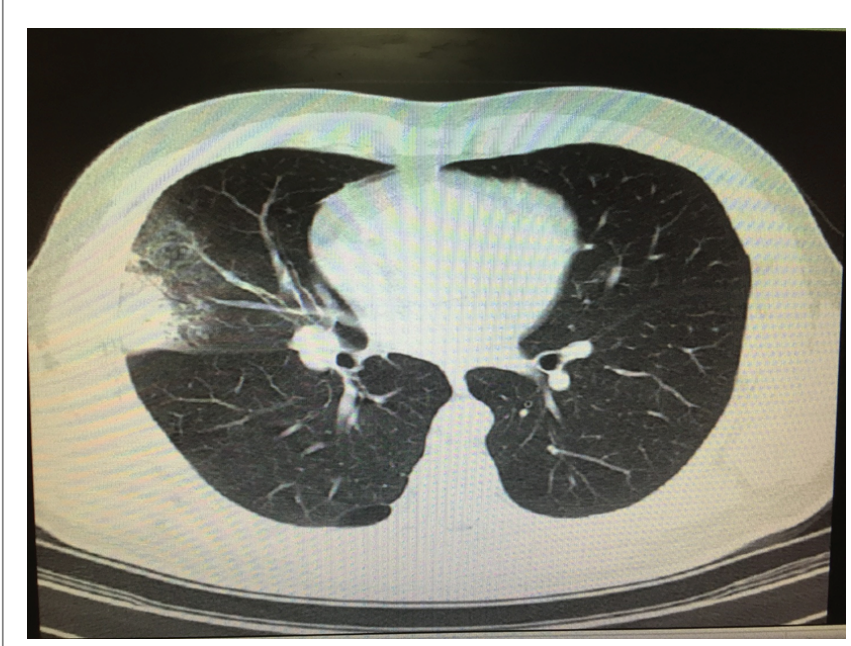

Figure 3: Chest CT scan. anticoagulation, ischaemic strokes occurred in 2 patients. They suggested that acute ischaemic stroke accompanying COVID-19 infection may have distinct characteristics, with implications for diagnosis and treatment [15].

Ashrafi F, et al. studied on COVID-19-related strokes in young adults, in a case series. In this series, six COVID-19 patients younger than 55 years of age with diagnosis of stroke were evaluated. The most common clinical symptoms include Fever, myalgia, cough, and dyspnea. The mean \pm standard deviation (SD) of National Institutes of Health Stroke Scale (NIHSS) for the patients was 10.16 \pm 7.13 (ranged 5-24). Middle cerebral artery (MCA) was reported as the most involved area (five in MCA versus one in basal ganglia), and the lung involvement score of majority of the patients was low (mean \pm SD: $13.16 \pm 6.49$ out of 24$)$. At the end, one patient was expired and rest discharged $[19,20]$.

Klok F, et al. studied on the incidence of thrombotic complications in patients with COVID-19 infection. They surveyed 184 ICUadmitted patients with COVID-19 infection to evaluate the incidence of the composite outcome of symptomatic acute pulmonary embolism (PE), deep-vein thrombosis, ischemic stroke, myocardial infarction or systemic arterial embolism. All patients received at least standard doses of thromboprophylaxis. The cumulative incidence of the composite outcome was $31 \%$, of which $27 \%$ included VTE and $3.7 \%$ included arterial thrombotic events. PE was reported as the most frequent thrombotic complication $(\mathrm{n}=25,81 \%)$. Due to the high incidence of thrombotic complications in ICU-admitted COVID-19 patients (31\%), they recommended pharmacological thrombosis prophylaxis in all COVID-19 patients admitted to the ICU, and strongly suggested to increase the prophylaxis toward high-prophylactic doses, even in the absence of randomized evidence [21].

Avula A, et al. reported four COVID-19 patients presenting acute stroke. They identified four patients who presented with radiographic confirmation of acute stroke and PCR-confirmed SARS-CoV-2 infection [10].

Oxley TJ, et al. reported five cases of COVID-19 infection with large-vessel stroke, in patients younger than 50 years of age. On admission of the patients, the mean of NIHSS was 17, consistent with severe large-vessel stroke. One patient had a history of stroke [22]. Stroke could be unrelated to age and the extent of lung involvement. However, different factors may play roles in co-occurrence of stroke and COVID-19 and its outcome.

As we know, timely assessment and hyperacute treatment is the key to minimize mortality and morbidity of patients with acute stroke.

Nevertheless, our findings suggest that ischaemic stroke linked to COVID-19 infection can occur in the context of a systemic highly prothrombotic state, supporting recommendations for immediate prophylactic anticoagulation with LMWH [23].

\section{Conclusion}

We recommend to follow-up the patient and keep on taking atorvastatin and anti-platelete medications (aspirin, plavix) beside risk factor evaluation, for patients with the same situation. Also, early therapeutic anticoagulation with LMWH could be considered as a beneficial approach to reduce thromboembolism in ischaemic stroke patients with COVID-19 infection, but must be balanced against the risk of intracranial haemorrhage, including haemorrhagic transformation of the acute infarct. Future studies with more cases are needed to assess prognostic factors. 


\section{References}

1. Li X, Zai J, Zhao Q, Nie Q, Li Y, et al. (2020) Evolutionary history, potential intermediate animal host, and cross-species analyses of SARS-CoV-2. J Med Virol 92: 602-611.

2. Karkhah S, Ghazanfari MJ, Shamshirian A, Panahi L, Molai M, et al. (2020) Clinical Features of Patients with Probable 2019 Novel Coronavirus Infected Pneumonia in Rasht, Iran: A Retrospective Case Series. Open Access Maced J Med Sci 8: 16-22.

3. Shahriarirad R, Khodamoradi Z, Erfani A, Hosseinpour H, Ranjbar K, et al. (2020) Epidemiological and clinical features of 2019 nove coronavirus diseases (COVID-19) in the South of Iran. BMC Infect Dis 20: 1-12.

4. Li YC, Bai WZ, Hashikawa T (2020) The neuroinvasive potential of SARS-CoV2 may play a role in the respiratory failure of COVID-19 patients. J Med Virol 92: 552-555.

5. Moriguchi T, Harii N, Goto J, Harada D, Sugawara H, et al. (2020) A first case of meningitis/encephalitis associated with SARSCoronavirus-2. Int J Infect Dis 94: 55-58.

6. Wildwing T, Holt $N$ (2020) Similarities between the neurological symptoms of COVID-19 and Functional Neurological Disorder: A systematic overview of systematic reviews and implications for future neurological healthcare services. MedRxiv.

7. Padda I, Khehra N, Jaferi U, Parmar MS (2020) The neurological complexities and prognosis of COVID-19. SN Compr Clin Med.

8. Poyiadji N, Shahin G, Noujaim D, Stone M, Patel S, et al. (2020) COVID19-associated acute hemorrhagic necrotizing encephalopathy: CT and MRI features. Radiology 296: E119-E120.

9. Al Saiegh F, Ghosh R, Leibold A, Avery MB, Schmidt RF, et al. (2020) Status of SARS-CoV-2 in cerebrospinal fluid of patients with COVID-19 and stroke. J Neurol Neurosurg Psychiatry 91: 846-848.

10. Avula A, Nalleballe K, Narula N, Sapozhnikov S, Dandu V, et al. (2020) COVID-19 presenting as stroke. Brain Behav Immun 87: 115-119.

11. Markus HS, Brainin M (2020) COVID-19 and stroke-A global World Stroke Organization perspective. Int J Stroke 15: 361-364.
12. Tang N, Li D, Wang X, Sun Z (2020) Abnormal coagulation parameters are associated with poor prognosis in patients with novel coronavirus pneumonia. J Thromb Haemost 18: 844-847.

13. Tang N, Li D, Wang X, Sun Z (2020) Abnormal coagulation parameters are associated with poor prognosis in patients with novel coronavirus pneumonia. Journal of Thrombosis and Haemostasis 18: 844-847.

14. Zhang Y, Xiao M, Zhang S, Xia P, Cao W, et al. (2020) Coagulopathy and antiphospholipid antibodies in patients with COVID-19. N Engl J Med 382: e38.

15. Reddy ST, Garg T, Shah C, Nascimento FA, Imran R, et al. (2020) Cerebrovascular Disease in Patients with COVID-19: A Review of the Literature and Case Series. Case Rep Neurol 12: 199-209.

16. Beyrouti R, Adams ME, Benjamin L, Cohen H, Farmer SF, et al. (2020) Characteristics of ischaemic stroke associated with COVID-19. J Neurol Neurosurg Psychiatry 91: 889-891.

17. Li Y, Wang M, Zhou Y, Chang J, Xian Y, et al. (2020) Acute Cerebrovascular Disease Following COVID-19: A Single Center, Retrospective, Observational Study. Stroke Vasc Neuro 5: e000431.

18. Lodigiani C, lapichino G, Carenzo L, Cecconi M, Ferrazzi P, et al. (2020) Venous and arterial thromboembolic complications in COVID-19 patients admitted to an academic hospital in Milan, Italy. Thromb Res 191: 9-14.

19. Mao L, Jin H, Wang M, Hu Y, Chen S, et al. (2020) Neurologic Manifestations of Hospitalized Patients with Coronavirus Disease 2019 in Wuhan, China. JAMA Neurol 77: 683-690.

20. Ashrafi F, Zali A, Ommi D, Salari M, Fatemi A, et al. (2020) COVID-19related strokes in adults below 55 years of age: a case series. Neurol Sci 41: 1985-1989.

21. Klok F, Kruip M, Van der Meer N, Arbous M, Gommers D, et al. (2020) Incidence of thrombotic complications in critically ill ICU patients with COVID-19. Thromb Res 191: 145-147.

22. Oxley TJ, Mocco J, Majidi S, Kellner CP, Shoirah H, et al. (2020) Largevessel stroke as a presenting feature of COVID-19 in the young. N Engl J Med 382: e60.

23. NHS (2020) Clinical guide for the management of stroke patients during the coronavirus pandemic. 